\title{
A teoria celular em livros didáticos de biologia: uma análise sobre as concepções acerca da natureza da ciência
}

\section{Cell Theory in biology textbooks: an analysis on concepcions about nature of science}

\author{
Elda Cristina Carneiro da Silva (elda.bio@ hotmail.com) \\ Universidade Federal do Paraná
}

Joanez Aparecida Aires (joanez.ufpr@gmail.com)

Universidade Federal do Paraná

Resumo: A apropriação da abordagem histórica-filosófica-sociológica pelos professores das disciplinas científicas tem sido apontada como potencialmente capaz de subsidiá-los para o enfrentamento de muitos dos problemas da educação em ciências. De modo geral, os livros didáticos são o instrumento pelo qual ocorre a inclusão desta abordagem nas aulas. Nosso objeto de análise consiste em seis livros didáticos do $1^{\circ}$ ano do ensino médio da disciplina biologia, aprovados no PNLD/2012 e PNLD/2018, com o objetivo de conhecer e refletir sobre as concepções acerca da natureza da ciência apresentadas nestes livros quando abordam a teoria celular. Utilizamos a abordagem qualitativa e quantitativa do tipo documental por meio da análise de conteúdo. $\mathrm{O}$ desenvolvimento das categorias de análise se deu a partir das visões deformadas ou ingênuas sobre ciência que podem estar sendo difundidas no ensino de ciências. Os resultados evidenciam indícios de mudanças nas concepções dogmáticas e hegemônicas sobre a ciência/cientistas, apesar do predomínio das categorias que expressam visões deformadas em ambas as edições do PNLD. Para que episódios históricos sejam apresentados numa perspectiva diferente daquela que vem predominando, sugerimos aos autores de livros didáticos que se alinhem aos estudos histórico-filosóficossociológicos sobre a ciência/biologia e apresentamos algumas considerações sobre a elaboração destes textos.

Palavras-chave: Natureza da ciência; Livros didáticos de biologia; Teoria celular.

Abstract: The appropriation of the historical-philosophical-sociological approach by teachers of scientific disciplines has been pointed out as potentially capable of subsidizing them to face many of the problems of science education. In general, textbooks are the instrument by which this approach is included in classes. Our object of analysis consists of six textbooks from the 1st year of high school of the biology discipline, approved in PNLD / 2012 and PNLD / 2018, with the objective of knowing and reflecting on the conceptions about the nature of science presented in these books when they approach the cell theory. We use the qualitative and quantitative approach of documentary type through content analysis. The development of the analysis categories took place from the deformed or naive views on science that may be being spread in

Recebido em: 18/01/2021

Aceito em: 24/02/2021 
science teaching. The results show evidence of changes in dogmatic and hegemonic conceptions about science and scientists, despite the predominance of categories that express deformed views in both editions of the PNLD. In order for historical episodes to be presented in a different perspective from the one that has predominated in biology books, we suggest that textbook authors align themselves with historical-philosophicalsociological studies on science / biology and present some considerations on the elaboration of these texts.

Keywords: Nature of science; Biology textbooks; Cell theory.

\section{INTRODUÇÃO}

Pesquisas e documentos oficiais referentes à educação em ciências têm indicado que a abordagem histórico-filosófica-sociológica na educação em ciências permite aos estudantes adquirirem conhecimento sobre a natureza da ciência (BRASIL, 2000; MATHEWS, 2012; ALLCHIN, 2017; BARBOSA; AIRES, 2018; MENDONÇA, 2020; KRUPCZAC; AIRES, 2020).

Assim como existem diversos pressupostos filosóficos sobre a ciência, há várias compreensões possíveis sobre o significado da expressão 'natureza da ciência' $(\mathrm{NdC})$. Moura (2014, p. 33) define que a NdC "envolve um arcabouço de saberes sobre as bases epistemológicas, filosóficas, históricas e culturais da ciência". Esta concepção foi adotada na nossa pesquisa, pois parece incorporar aspectos importantes das reflexões epistemológicas sobre a construção do conhecimento científico.

Eflin, Glennan e Reisch (1999) e Allchin (2017) questionam os pontos de consenso sobre a NdC defendidos por autores como Gil Pérez et al., 2001; Cachapuz et al., 2005, Lederman, 2006. Estes aspectos caracterizam as chamadas abordagens essencialistas e relacionam-se à dinamicidade da ciência, à não existência de um método científico universal, à influência de fatores sociais, históricos, culturais na atividade científica, à dependência que a observação tem da teoria, ao caráter experimental da ciência, à participação da criatividade na construção do conhecimento científico, dentre outros aspectos.

Estas abordagens, segundo Mendonça (2020), receberam críticas que contribuíram para a argumentação favorável ao ensino de $\mathrm{NdC}$ contextualizado a partir da análise de casos da ciência (casos históricos ou contemporâneos), por meio dos quais é possível 
investigar, em cada episódio, aspectos que os caracterizam de acordo com o contexto da produção do conhecimento ${ }^{1}$.

Allchin, Andersen e Nielsen (2014) distinguem os tipos de compreensões que os estudantes podem obter a partir de episódios da ciência. Por exemplo, os casos contemporâneos da ciência permitem reflexões sobre a NdC, tais como incerteza, subjetividade, o papel do financiamento e interesses políticos. Já os casos históricos, auxiliam na compreensão de como as controvérsias científicas foram solucionadas.

Isto significa que o trabalho científico não é constituído de aspectos homogêneos e estanques. Podemos considerar, inclusive, que algumas características da ciência na atualidade não foram contempladas pelos estudos clássicos da filosofia da ciência. De acordo com Tala e Vesterinen (2015), devemos estar atentos, por exemplo, ao desenvolvimento de modelagem e simulações como novas abordagens metodológicas, proporcionadas pelo rápido desenvolvimento de computadores durante as últimas décadas.

Além disso, Allchin, Andersen e Nielsen (2014) chamam a atenção para os problemas advindos das listas consensuais sobre a $\mathrm{NdC}$ :

[...] as listas de consenso confundem característica epistemológicas, ontológicas, sociológicas, éticas e filosóficas da ciência e - sendo gerais em muitos domínios científicos - tendem a agregar de forma imprecisa as práticas científicas em domínios específicos e distorcer representações históricas da ciência (ALLCHIN; ANDERSEN; NIELSEN, 2014, p.463).

Todavia, levando em conta a defesa de alguns autores, de que o essencialismo sobre a NdC pode ser apropriado no aspecto pedagógico (EFLIN; GLENNAN; REISCH, 1999; TALA; VESTERINEN, 2015), consideramos coerente refletir sobre as possibilidades de concepções sobre a $\mathrm{NdC}$ que a educação em ciências reforça por ação ou omissão. De acordo com Cachapuz et al. (2005), entendemos por ação toda forma de menção, explicação que incide explicitamente em visões deformadas da atividade científica $^{2}$, enquanto a omissão relaciona-se à ausência de referências a elementos que poderiam evitar incorrer nos reducionismos e distorções típicos.

\footnotetext{
1 A autora esclarece que um determinado contexto poderá ser mais propício para tratar de aspectos sociológicos e econômicos da ciência, enquanto outros poderão favorecer um entendimento mais profundo dos aspectos cognitivos da ciência.

2 O termo 'visões deformadas' da ciência foram cunhados por Gil Pérez et al. (2001) e Cachapuz et al. (2005) para caracterizar tipos de concepções epistemológicas acerca da natureza da ciência que muito se distanciam da forma pela qual se constroem os conhecimentos científicos. Estes referenciais teóricos Recebido em: 18/01/2021
}

Aceito em: 24/02/2021 
Edição Especial: I SSAPEC - Simpósio Sul-Americano de Pesquisa em Ensino de Ciências ISSN: 2595- $4520 \quad$ Vol. 4, n. 3. 2021

Campos e Cachapuz (1997, p. 24) acreditam que os livros didáticos veiculam "concepções sobre a natureza da ciência e da construção do conhecimento científico" e que é possível, pela análise do conteúdo destes livros, identificar tais concepções. Na educação em biologia, um conteúdo fundamental apresentado nestes livros é a teoria celular, uma vez que esta teoria permitiu o reconhecimento da semelhança microscópica entre todos os seres vivos devido a uma estrutura comum: a célula (SILVA, 2014).

Ao analisar as concepções a respeito da $\mathrm{NdC}$ apresentadas nos livros didáticos de biologia do PNLD/2012 e em livros universitários usados como referência para estes, quando abordam a teoria celular, Silva (2014) constatou uma predominância das categorias referentes às visões deformadas ou ingênuas sobre ciência em relação às categorias de enfrentamento destas visões.

Tendo por base tais reflexões, o objetivo deste estudo consistiu em conhecer e refletir sobre quais concepções a respeito da $\mathrm{NdC}$ são apresentadas em livros didáticos de biologia, aprovados pelo PNLD/2012 e PNLD/2018, quando abordam a teoria celular. Após apresentação e discussão dos resultados obtidos da análise desses livros, desenvolvemos algumas reflexões e contribuições epistemológicas para a construção de um texto sobre a teoria celular no livro didático.

\section{2.}

Esta é uma pesquisa de abordagem quali-quantitativa, do tipo documental e bibliográfica (LAKATOS; MARCONI, 2003), sendo as análises realizadas por meio da metodologia da análise de conteúdo, proposta por Moraes (1999).

Moraes (1999) descreve o processo de análise de conteúdo em cinco etapas: 1) preparação das informações; 2) unitarização ou transformação do conteúdo em unidades de análise e de contexto; 3) categorização ou classificação das unidades em categorias definidas a priori ou a partir dos dados (emergentes); 4) descrição, onde se comunica os significados presentes nas unidades de análise; 5) interpretação.

Na etapa de preparação das informações, identificamos os livros didáticos a serem analisados e demos início ao processo de codificação dos materiais, a fim de

foram adotados na pesquisa realizada por Silva (2014) para a elaboração das categorias de análise em livros didáticos de biologia. 
convencionar um código que possibilite identificar rapidamente cada elemento da amostra de documentos. O objeto de estudo corresponde a 6 livros didáticos, referentes ao $1^{\circ}$ ano do ensino médio da disciplina biologia: 3 livros aprovados no PNLD/2012 e suas edições mais recentes aprovadas no PNLD/2018³.

Os livros selecionados para análise e seus respectivos códigos de identificação encontram-se no quadro a seguir no Quadro 1.

Quadro 1 - obras aprovadas no PNLD/2012 e PNLD/2018 - biologia com referência aos capítulos que tratam do tema teoria celular.

\begin{tabular}{|c|c|}
\hline $\begin{array}{c}\text { CÓDIGO DE } \\
\text { IDENTIFICAÇÃO }\end{array}$ & REFERÊNCIAS \\
\hline LD1 & $\begin{array}{l}\text { LOPES, Sônia; ROSSO, Sérgio. Citologia e envoltórios } \\
\text { celulares. In: } \quad \text {. Bio. São Paulo: Saraiva, v.1, 2010, p. } \\
\text { 256-258; 263-264. }\end{array}$ \\
\hline LD2 & $\begin{array}{l}\text { SILVA JÚNIOR, César da; SASSON, Sezar; CALDINI } \\
\text { JÚNIOR, Nelson. In: } \\
\text { dos seres vivos. Biologia. São Paulo: Saraiva, v. } 1,12^{a} \text { ed., } \\
\text { 2016, p. 200-201. }\end{array}$ \\
\hline LD3 & $\begin{array}{l}\text { LINHARES, Sérgio; GEWANDSZNAJDER, Fernando. Uma } \\
\text { visão geral da célula. In: } \\
\text { Ática, v. } 1,2010 \text {, p. } 90-91 .\end{array}$ \\
\hline LD1N & $\begin{array}{l}\text { LOPES, Sônia; ROSSO, Sérgio. Citologia e envoltórios } \\
\text { celulares. In: } \quad \text {. Bio. São Paulo: Saraiva, v.1, 2016, p. } \\
\text { 194-196; p. 182. }\end{array}$ \\
\hline evistan & $\begin{array}{l}\text { SILVA JÚNIOR, César da; SASSON, Sezar; CALDINI } \\
\text { JÚNIOR, Nelson. In: } \\
\text { dos seres vivos. Biologia. São Paulo: Saraiva, v. } 1,10^{a} \text { ed., } \\
\text { 2010, p. 200-201. }\end{array}$ \\
\hline LD3N & $\begin{array}{l}\text { LINHARES, Sérgio; GEWANDSZNAJDER, Fernando. Uma } \\
\text { visão geral da célula. In: } \\
\text { Ática, v. } 1,3^{\text {a }} \text { ed., 2016, p. } 90-91 .\end{array}$ \\
\hline
\end{tabular}

$\mathrm{Na}$ etapa de unitarização, identificamos as unidades de análise e definimos unidades mais amplas relacionadas às concepções sobre a natureza da ciência nos livros didáticos, as unidades de contexto. Cada unidade recebeu códigos adicionais associados ao sistema de identificação elaborado na etapa anterior.

\footnotetext{
${ }^{3}$ Primeiramente foram selecionados apenas os livros cujos autores são os mesmos nas duas versões do PNLD em análise (substituições ou acréscimo de pelo menos um autor foi motivo de exclusão do livro). O segundo critério foi identificar os livros do PNLD/2012 que apresentaram altas porcentagens de visões deformadas sobre a ciência e altas porcentagens de enfrentamento destas concepções em pesquisa anterior realizada por Silva (2014).
} 
Na terceira etapa da análise de conteúdo proposta por Moraes (1999) ocorreu a classificação dos dados por semelhança ou analogia, segundo critérios semânticos, os quais originaram categorias temáticas.

Construímos as categorias definidas a priori, a partir das visões deformadas descritas por Gil-Perez et al. (2001), as quais podem ser consideradas visões ou concepções epistemológicas distorcidas, empobrecidas ou ingênuas acerca da $\mathrm{NdC}$, as quais a educação em ciências pode estar transmitindo, de forma velada ou explícita (GIL PÉREZ et al., 2001; CACHAPUZ et al., 2005). A partir destas categorias, elaboramos um segundo conjunto de categorias, as quais estão relacionadas ao enfrentamento destas concepções. O Quadro 2 contempla os dois conjuntos de categorias utilizados na análise de conteúdo desenvolvida nesta pesquisa.

Quadro 2 - categorias a priori utilizadas na análise dos livros didáticos de biologia - PNLD/2012 e PNLD/2018.

\begin{tabular}{|c|c|}
\hline $\begin{array}{c}\text { CATEGORIAS REFERENTES A VISÕES } \\
\text { DEFORMADAS OU INGÊNUAS SOBRE } \\
\text { A CIENCIA }\end{array}$ & $\begin{array}{c}\text { CATEGORIAS REFERENTES AO } \\
\text { ENFRENTAMENTO/SUPERAÇÃO DE } \\
\text { VISÕES DEFORMADAS OU INGÊNUAS } \\
\text { SOBRE A CIENCIA }\end{array}$ \\
\hline Ciência não influenciada por fatores externos. & Ciência influenciada por fatores externos. \\
\hline Ciência como atividade individual. & Ciência como atividade coletiva. \\
\hline $\begin{array}{l}\text { Observação neutra e em busca da descoberta } \\
\text { científica. }\end{array}$ & Observação influenciada por uma teoria. \\
\hline Método científico clássico. & Pluralismo metodológico. \\
\hline $\begin{array}{l}\text { Conhecimento } S \text { científico verdadeiro } \partial \mathrm{e} \\
\text { definitivo. }\end{array}$ & Caráter histórico e dinâmico da ciência. \\
\hline $\begin{array}{llll}\begin{array}{l}\text { Fragmentação } \\
\text { conhecimento. }\end{array} & \text { e/ou } & \text { simplificação } & \text { do } \\
\end{array}$ & Unificação do conhecimento científico. \\
\hline Linearidade da ciência. & Rupturas e/ou controvérsias científicas. \\
\hline
\end{tabular}

O último momento da análise é constituído pela quarta e pela quinta etapa da metodologia da análise de conteúdo proposta por Moraes (1999), a descrição e a interpretação dos resultados, respectivamente, as quais apresentamos simultaneamente na próxima seção destinada à análise quali-quantitativa dos livros didáticos e discussão dos resultados.

\section{DESCRIÇÃO E INTERPRETAÇÃO DOS RESULTADOS DA ANÁLISE DOS LIVROS DO PNLD/2012 E PNLD/2018- BIOLOGIA}


Após a categorização das unidades de análise com base nas categorias a priori e emergentes explicitadas anteriormente, calculamos as frequências em quantidade e porcentagem das unidades de análise em cada categoria, referentes às visões deformadas ou ingênuas sobre a ciência, como também ao enfrentamento de tais visões. O resultado desta análise quantitativa do conjunto dos livros didáticos de biologia do PNLD/2012 e PNLD/2018 selecionados é apresentado a seguir.

No decorrer desta seção apresentamos a descrição qualitativa dos dados, acompanhada da interpretação, etapa final do modelo de análise de conteúdo adotado nesta pesquisa (MORAES, 1999).

Ao considerarmos o total de 45 unidades de análise dos livros do PNLD/2012 e 46 unidades de análise dos livros do PNLD/2018- biologia, verificamos os resultados no Quadro 3.

Quadro 3 - frequência em quantidade e porcentagem das unidades de análise dos livros do PNLD/2012 e PNLD/2018- biologia nos dois conjuntos de categorias utilizados para análise.

\begin{tabular}{|c|c|c|c|c|}
\hline (e & \multicolumn{2}{|c|}{ PNLD 2012} & \multicolumn{2}{|c|}{ PNLD 2018} \\
\hline Conjuntos de categorias & $n^{0}$ de UA & $\%$ de UA & $n^{0}$ de UA & $\%$ de UA \\
\hline $\begin{array}{c}\text { Visões deformadas ou ingênuas } \\
\text { sobre a ciência. }\end{array}$ & 31 & $68,9 \%$ & 29 & $63 \%$ \\
\hline $\begin{array}{l}\text { Enfrentamento de visões deformadas } \\
\text { ou ingênuas sobre a ciência. }\end{array}$ & 14 & $31,1 \%$ & 17 & $37 \%$ \\
\hline TOTAL & 45 & $100 \%$ & 46 & $100 \%$ \\
\hline
\end{tabular}

Um aspecto positivo que pode ser observado a partir destes números é que no PNLD 2018 encontramos menos visões deformadas e mais visões de enfrentamento. Isso significa que aos poucos vamos percebendo uma inversão do que se ensina e se aprende sobre a construção da ciência. Ou seja, vamos nos afastando de uma compreensão mais ingênua e simplista e nos aproximando de uma compreensão mais realista da ciência, no sentido que esta corresponde a uma construção humana, contextual, controversa, entre outros aspectos.

Em relação às visões deformadas sobre a ciência nos livros selecionados do $\mathrm{PNLD} / 2012$ e PNLD/2018, as categorias mais frequentes foram 'observação/descrição neutra e em busca da descoberta científica', 'ciência como atividade individual' e a categoria emergente 'relato histórico centrado no presente', que caracteriza a distorção 
histórica chamada whiggismo (PRESTES, 2010). Esta classificação justificou-se por terem sido detectados relatos anacrônicos, sem relação direta com as características da 'visão aproblemática e ahistórica' (CACHAPUZ et al., 2005), a qual originou a categoria 'conhecimento científico verdadeiro e definitivo'.

A predominância das categorias referentes às visões deformadas sobre a ciência nos livros do PNLD/2012 e PNLD/2018 selecionados neste trabalho (Quadro 3), tem forte participação da categoria 'observação/descrição neutra e em busca da descoberta científica', o que demonstra a forte influência hegemônica do método empírico-indutivo baconiano na concepção sobre ciência dos autores ${ }^{4}$. Enfatizamos o aumento das unidades de análise da edição mais recente do LD1 relativas a esta categoria, bem como uma redução das unidades de análise da edição mais recente do LD2 referentes à categoria 'relato histórico centrado no presente'.

Quanto ao enfrentamento das visões deformadas nos livros selecionados do PNLD/2012 e PNLD/2018, as duas categorias mais frequentes foram 'ciência como atividade coletiva' e 'caráter histórico e dinâmico da ciência'. Destacamos o aumento das unidades de análise da edição mais recente do LD2 relacionadas à categoria 'ciência como atividade coletiva', o que levou a não identificação da categoria oposta neste livro, relevante para superação da ideia do conhecimento científico como obra de gênios isolados, ignorando a sua construção coletiva.

Para ilustrar os resultados apresentados, podemos contemplar um excerto referente à categoria emergente 'relato histórico centrado no presente':

\section{[...] O que esse cientista viu foram as paredes celulares das células que formam a cortiça, pois a imagem foi obtida a partir de células mortas. A fotomicrografia aqui mostrada ilustra o que Hooke observou, porém com aumento muito maior [...] (LD1, 2016).}

Neste caso, o autor tenta associar o conceito de célula construído pela citologia no século XIX, com o trabalho de Hooke no século XVII, o qual, segundo Martins (2011), não tinha interesse 'biológico', e sim microscópico.

\footnotetext{
${ }^{4}$ Francis Bacon (1561-1626) apresentou em sua obra Novum Organum no século XVII a teoria da indução, em oposição ao método Aristotélico. Bacon teve a intenção de formular um novo método científico de base sólida, que desse segurança para a procura da verdade, por meio da experiência e observação (SILVA, 2008).
} 
Em contrapartida, a nova edição deste livro apresenta uma versão do episódio por meio de um relato que mostra o caráter histórico e dinâmico da ciência e, implicitamente, seu caráter coletivo, conforme podemos constatar:

\begin{abstract}
Apesar de ter usado a palavra 'célula', Hooke não estava se referindo à unidade básica, estrutural e fisiológica dos seres vivos, como nós entendemos a célula hoje. Hooke não cogitou que estava vendo as paredes das células vegetais. Esse entendimento só surgiu mais tarde (LD1, 2016).
\end{abstract}

Consideramos os resultados apresentados como indícios de mudanças nas concepções dogmáticas sobre a ciência e os cientistas, apesar do predomínio das categorias que evidenciam as visões ingênuas. A maior frequência da categoria 'observação neutra e em busca da descoberta científica' nos motivou a tecer alguns comentários acerca de requisitos necessários à elaboração de um texto que não aponte para uma ciência com características empírico-indutivistas.

\title{
4. ALGUMAS CONTRIBUIÇÕES EPISTEMOLÓGICAS PARA A CONSTRUÇÃO DE UM TEXTO SOBRE TEORIA CELULAR NO LIVRO DIDÁTICO
}

Os dados constituídos nesta pesquisa nos permitem contribuir pontualmente com algumas reflexões sobre terminologias utilizadas ao se escrever acerca da história da ciência em livros didáticos do ensino médio, em especial à palavra descoberta, por sua recorrência nas unidades de análise e também pelas interpretações que subjazem a este termo.

Para isto e, levando em conta o objetivo central deste estudo consideramos relevante destacar os comentários de Martins (2004) acerca de elementos científicos em obras historiográficas, ainda que nosso objeto de investigação sejam livros da educação básica e da educação superior, os quais, apesar de não possuírem este perfil, veiculam informações sobre a história da ciência.

Sobre as intenções das proposições escritas por historiadores, Martins (2004) explica que:

O que vai determinar se o historiador está fazendo afirmações científicas ou não é a terminologia que ele utiliza ao fazer uma descrição histórica. Se ele escrever que 'Fulano observou que [isto e aquilo]', estará simultaneamente afirmando que isto ou aquilo existe ocorre ou é possível. Se colocar que 
'Fulano afirmou ter observado que [isto e aquilo]', o historiador não estará se comprometendo com a realidade dos fenômenos que Fulano diz ter observado (MARTINS, 2004, p. 124).

Naturalmente, esta advertência de Martins (2004) se aplica não só ao historiador da ciência, mas também aos autores de livros didáticos, os quais podem manter-se imparciais ou não em relação aos fatos científicos que descrevem em seus textos, dependendo dos termos utilizados ou da forma que constroem sua narrativa.

Ao investigar princípios historiográficos que não devem ser negligenciados quando o docente se propõe a elaborar textos didáticos que utilizem a abordagem histórica, Vital e Guerra (2016) advertem:

[...] a elaboração dos textos e materiais didáticos com enfoques históricos requer uma seleção fundamentada de fontes históricas de modo a apresentar o conhecimento científico e suas condições de produção em uma perspectiva que viabilize um ensino de ciências capaz de estimular o interesse dos alunos (VITAL; GUERRA, 2016, p. 352).

As autoras ressaltam que a busca da qualidade pedagógica na elaboração de textos para o ensino de ciências proporciona a possibilidade de incentivar a percepção de lacunas no conhecimento dos cientistas, o que caracteriza a ciência como um processo inacabado (VITAL; GUERRA, 2016).

Segundo Martins (2004, p. 124), existem certos termos que também determinam o comprometimento do autor e que aparecem com frequência na literatura historiográfica, como é o caso do termo descobriu, pois "a afirmação de que uma pessoa descobriu um fenômeno, pressupõe que o fenômeno existe". Ou seja, neste caso o autor está assumindo e veiculando uma concepção de ciência empirista, na qual o sujeito/observador é neutro, sendo o fenômeno descoberto independentemente da teoria que orientou o olhar do observador. Este consiste em um exemplo clássico de visão deformada de ciência, de acordo com Gil-Perez et al. (2001).

Durante a análise dos livros didáticos, percebemos que mesmo quando os autores buscam apresentar ideias que evitem incorrer numa visão deformada do trabalho científico, como por exemplo, quando reforçam o 'caráter histórico e dinâmico da ciência' ou a 'ciência como atividade coletiva', é muito comum o uso de palavras como descoberta, observar, descrever, generalizar, dentro de um contexto que remete a uma ciência de caráter empírico-indutivista, herança baconiana. 
Edição Especial: I SSAPEC - Simpósio Sul-Americano de Pesquisa em Ensino de Ciências

ISSN: 2595- $4520 \quad$ Vol. 4, n. 3. 2021

Conforme constatamos na reconstrução histórica do desenvolvimento da teoria celular (SILVA, 2014; SILVA; AIRES, 2016), sem dúvida, esta característica esteve presente na prática dos pesquisadores envolvidos nos diversos episódios que colaboraram para a construção desta teoria. No entanto, uma abordagem históricofilosófica deste conteúdo, requer uma releitura destes acontecimentos, com o resgate de ideias mais alinhadas com o contexto de produção deste conhecimento, uma vez que não poderíamos esperar que existissem (ou existam) discussões epistemológicas entre os pesquisadores sobre o seu fazer científico.

Esta tarefa vem sendo desempenhada por historiadores e filósofos da ciência de forma sistemática desde o século passado, mas não parece integrar os estudos e procedimentos dos cientistas, que se ocupam dos mecanismos internos da ciência, de forma que a simples pesquisa em fontes primárias não nos fornece diretamente elementos que favoreçam a reflexão e compreensão sobre a prática científica. Decorre desse fato a importância dos estudos epistemológicos associados aos estudos historiográficos da ciência.

O termo descoberta, conforme assinalado anteriormente, por exemplo, foi muito utilizado pelos autores dos livros didáticos de modo geral, tanto nas unidades de análise que incorrem em visões deformadas sobre a ciência quanto naquelas que buscam o enfrentamento de tais visões.

Esta constatação demonstra a forte influência do hegemônico método empíricoindutivo na concepção sobre ciência dos autores, ainda quando estes se propõem a apresentar a ciência numa perspectiva processual, coletiva e dinâmica. Podemos constatar essa tendência, por exemplo, no seguinte excerto: “À época em que a teoria foi enunciada, os vírus - descobertos pouco antes de 1900 - ainda não eram conhecidos [...]" (LD2, 2010; LD2N, 2016).

Nestes casos e em outros semelhantes, sugerimos uma breve explicação a respeito dos problemas inerentes ao uso da palavra descoberta no contexto da ciência ou sua substituição por termos como: identificados ou reconhecidos.

Outro exemplo bem claro do uso da palavra descoberta de forma descontextualizada, com a aparente intenção do autor, pode ser verificado na unidade de análise: "Com base nessas e em outras descobertas, elaborou-se a teoria celular [...]" 
(LD3N, 2016). Recomendamos, nesta situação, o uso do termo conhecimentos ou novos conhecimentos no contexto da frase.

Batisteti, Araújo e Caluzi (2009) discutem o significado da palavra descoberta no contexto científico. Segundo os autores, esta palavra é utilizada frequentemente tanto em livros didáticos quanto em textos de divulgação científica de um modo geral e destacam a importância de sermos cautelosos ao utilizar este termo, ao esclarecer o significado da palavra descoberta no âmbito da biologia em diferentes contextos:

Podemos dizer que Robert Hooke não descobriu a célula, pois, embora tenha chamado a estrutura que visualizou de célula, assim como de outras denominações, o que ele descobriu foram 'caixas cheias de ar que explicavam a leveza e a flexibilidade da cortiça', algo bastante diferente do que mais tarde veio a ser estabelecido como a "célula" dos seres vivos. Por sua vez, talvez possamos dizer que Robert Brown 'descobriu' o núcleo, ou seja, cunhou o termo para a estrutura que até hoje reconhecemos como tal na célula, mesmo não tendo uma função universal e indispensável. Pelo mesmo raciocínio, podemos dizer que um botânico, quando, em uma pesquisa de campo, identifica uma nova espécie vegetal, ele a 'descobriu' (BATISTETI; ARAÚJO; CALUZI, 2009, p. 36).

Os autores ampliam a discussão apresentando as ideias de Aaron J. Ihde ${ }^{5}$, sobre o caráter inevitável de uma descoberta numa determinada época oportuna, sendo que tal oportunidade baseia-se especialmente, segundo o pesquisador, no acúmulo de bases fundamentais do conhecimento necessárias a uma descoberta, o que está relacionado ao caráter coletivo da descoberta científica.

Conforme discutido anteriormente, a construção do conhecimento científico é uma tarefa na qual participam vários pesquisadores em diferentes épocas e contextos, por essa razão, segundo Batisteti, Araújo e Caluzi (2009, p. 38), existe "a dificuldade em atribuir a um único indivíduo o mérito de uma descoberta”.

Estas constatações vão ao encontro das ideias de Cachapuz et al. (2005) quando correlacionam duas visões deformadas sobre a ciência, amplamente detectadas na nossa análise: "individualista e elitista" e "empírico-indutivista e ateórica". Os autores afirmam que:

\begin{abstract}
A imagem individualista e elitista do cientista traduz-se em iconografias que representam o homem de bata branca no seu inacessível laboratório, repleto de estranhos instrumentos. Desta forma, constatamos uma [...] grave deformação: a que associa o trabalho científico, quase exclusivamente, com esse trabalho no laboratório, onde o cientista experimenta e observa,
\end{abstract}

\footnotetext{
${ }^{5}$ Autor de pesquisas e publicações sobre a história da ciência, na área da química (1909-2000). 
Edição Especial: I SSAPEC - Simpósio Sul-Americano de Pesquisa em Ensino de Ciências

ISSN: 2595- $4520 \quad$ Vol. 4, n. 3. 2021

procurando o feliz ‘descobrimento' (CACHAPUZ et al., 2005, p. 44-45, grifo do autor).

Martins (1999, p. 281, tradução nossa) ao propor condições para se atribuir a alguém o descobrimento de um fenômeno, manifesta-se sobre esta questão afirmando que "o fato de atribuir um descobrimento científico a um indivíduo quer dizer atribuirlhe um mérito científico, e qualquer discussão como essa termina vinculada a outros valores (que não são científicos)". Segundo o autor, à época do artigo, o conceito de descobrimento não havia sido analisado de forma mais profunda por historiadores e filósofos da ciência ao longo do tempo, de forma que em trabalhos historiográficos encontravam-se muitas descrições dos descobrimentos, sem análise, como se seu significado já fosse algo evidente.

Alguns anos depois, Martins (2006, p. 186) tece algumas considerações sobre as consequências de versões populares acerca da natureza do trabalho científico, como a ideia veiculada de que "a ciência seria construída através de uma série de descobertas que podem ser associadas a datas precisas e a autores precisos."

Versões como estas foram encontradas em nossa análise, tais como no exemplo: "Na década de 1820, o botânico escocês Robert Brown (1777-1858) [...] descobriu um pequeno corpo no interior de vários tipos de células e o chamou de núcleo" (LD3, 2010; LD3N, 2016).

Atualmente, ainda não encontramos trabalhos que trazem uma análise detalhada sobre o conceito de descoberta no contexto do uso em textos de livros didáticos e este pode ser um entrave à superação do uso desta palavra com tanta frequência nos textos dos livros didáticos.

\section{INFORMAÇÕES HISTÓRICAS INCORRETAS}

Durante as categorizações, foram detectados também equívocos de informações, tendo-se por base a reconstrução histórica da teoria celular pautada em fontes primárias e secundárias, apresentada por Silva (2014) e Silva e Aires (2016). Haveria, dessa forma, potencial para a emergência de uma categoria denominada 'informação histórica incorreta'. 
No entanto, ao se praticar o critério da exclusividade da metodologia proposta por Moraes (1999), no qual uma mesma unidade de análise não pode ser incluída em mais de uma categoria, optou-se por incluí-las em categorias a priori, por considerarmos mais enriquecedor para compor a resposta ao nosso problema de pesquisa, que trata de identificar quais concepções sobre a natureza da ciência são veiculadas nos livros de biologia, no que concerne ao tema teoria celular.

Dos livros selecionados para este estudo, a obra LD1 do PNLD/2012 destacou-se quanto às informações incorretas. Selecionamos duas unidades de contexto deste livro no quadro seguinte (Quadro 4) e em seguida comentamos seus equívocos e o que foi observado na sua edição mais recente do PNLD/2018.

Quadro 4- informações históricas incorretas encontradas em unidades de análise dos livros do PNLD/2012- biologia.

\begin{tabular}{|c|l|}
\hline CÓDIGO & \multicolumn{1}{c|}{ UNIDADES DE CONTEXTO } \\
\hline LD1.2 & $\begin{array}{l}\text { A citologia teve seu início com as observações do cientista inglês Robert Hooke } \\
(1635-1703) .\end{array}$ \\
\hline LD1.8 & $\begin{array}{l}\text { Em 1838, dois pesquisadores alemães, Matthias Schleiden (1804-1881) e } \\
\text { Theodor Schwann (1810-1882), formularam a teoria celular, segundo a qual } \\
\text { todos os seres vivos são formados por células. [...] }\end{array}$ \\
\hline
\end{tabular}

Na unidade de contexto LD1.2, a informação incorreta ocorre quando se atribui o início da citologia (estudo da célula) à Robert Hooke, o qual, conforme já esclarecemos anteriormente, não tinha intenção de investigar a célula, mas testar as lentes de seu microscópio a partir da observação de diversos materiais (MARTINS, 2011; PRESTES, 2011). Como argumenta Prestes (1997), Hooke foi o primeiro a observar uma estrutura que denominou de célula, mas isso não nos autoriza a considerá-lo o fundador da citologia, porque nada nos garante que ele tenha observado uma célula tal como a compreendemos atualmente.

Na edição do PNLD/2018 constatamos a superação deste equívoco na unidade de análise LDN1.11: “Após os trabalhos de Hooke, outros cientistas se interessaram pelo estudo microscópico dos seres vivos, desenvolvendo assim, a Citologia”. Esta informação está alinhada com a construção histórica e coletiva do trabalho científico para a consolidação da citologia.

Em relação à unidade de contexto LD1.8, a elaboração da teoria celular parece ser atribuída a apenas Schleiden e Schwann. Analisando a reconstrução histórica desta 
teoria, identifica-se a participação de diversos cientistas, em diferentes épocas e contextos. Além disso, reconhecendo os estudos de Schleiden com os vegetais publicados em $1838^{6}$, Schwann generaliza a teoria celular para os animais e vegetais, na sua clássica publicação no ano de $1839^{7}$. Este trecho do LD1 também veicula a ideia de que ambos os cientistas realizaram suas pesquisas em conjunto, o que não ocorreu, conforme a literatura.

$\mathrm{Na}$ versão do PNLD/2018, apenas a correção do ano foi privilegiada, conforme podemos observar na unidade de contexto LDN1.12: "No final da década de 1830, dois pesquisadores alemães Matthias Schleiden e Theodor Schwann, formularam a teoria celular, segundo a qual todos os seres vivos são formados por células [...]”. A ideia de trabalho em dupla permanece, ignorando as contribuições de outros pesquisadores a partir da primeira formulação desta teoria.

De acordo com Silva (2014), consideramos que as informações incorretas ou omissões comprometem a aprendizagem, uma vez que se constituem em erros conceituais e/ou históricos. É importante que, ao optarem pela história da ciência, os autores dos livros didáticos preocupem-se em apresentar uma narrativa coerente com os registros historiográficos, a fim de favorecer a discussões sobre a natureza da ciência de acordo com a forma pela qual o conhecimento científico é construído.

\section{CONSIDERAÇÕES FINAIS}

Neste estudo, levamos em consideração os pontos de consenso a respeito da natureza da ciência, sob o argumento de que são pedagogicamente adequados para alcançar nosso objetivo: conhecer e refletir sobre quais concepções a respeito da $\mathrm{Ndc}$ são apresentadas em livros didáticos de biologia aprovados pelo PNLD/2012 e pelo PNLD/2018 quando abordam a teoria celular.

Enfatizamos como aspecto positivo dos achados o aumento, ainda que incipiente, do enfrentamento das visões ingênuas sobre a ciência considerando os livros selecionados do PNLD/2018 e suas antigas edições que constam no PNLD/2012. Consideramos esse resultado representativo de um esforço dos autores dos livros

\footnotetext{
${ }^{6}$ Contributions to Phytogenesis.

${ }^{7}$ Microscopical researches into the accordance in the structure and growth of animals and plants. Recebido em: 18/01/2021

Aceito em: 24/02/2021
} 
Edição Especial: I SSAPEC - Simpósio Sul-Americano de Pesquisa em Ensino de Ciências

ISSN: 2595- $4520 \quad$ Vol. 4, n. 3. 2021

didáticos na busca pela superação de concepções que não representam a forma como os conhecimentos são construídos, o que pode ser indício de um movimento que resultaria num processo de mudança das visões sobre a natureza da ciência preponderantemente veiculadas pelos livros didáticos e, consequentemente, poderá levar a uma melhora na qualidade da aprendizagem de conteúdos biológicos.

Para potencializar este movimento, sugerimos aos autores de livros didáticos que se apropriem de estudos histórico-filosóficos-sociológicos sobre a ciência/biologia a fim de que os episódios históricos da ciência sejam apresentados nos livros de biologia numa perspectiva mais alinhada ao processo de construção do conhecimento científico.

Como aspecto negativo, identificamos nos livros analisados em ambas as edições o predomínio da concepção de ciência neutra, com ênfase na descoberta e algumas informações históricas incorretas. Como colaboração à superação destas visões ingênuas sobre ciência, foi possível apresentar alguns comentários/orientações para a elaboração de um texto voltado para o livro didático de biologia a partir da reconstrução histórica dos episódios envolvidos no processo de elaboração da teoria celular.

Este resultado também nos leva a considerar a importância deste programa de avaliação (PNLD), onde é possível identificar critérios que consideram a busca pela superação de visões deformadas ou ingênuas sobre a ciência, fator que certamente influenciou no aumento do enfrentamento destas visões, as quais se faziam mais presentes em edições anteriores.

\section{REFERÊNCIAS}

ALLCHIN, Douglas. Beyond the consensus view: whole science. Canadian Journal of Science and Mathematics and Technology Education, Heidelberg, v. 17, n. 1, p. 1826, 2017.

ALLCHIN, Douglas; ANDERSEN, Hanne Moller; NIELSEN, Keld. Complementary approaches to teaching nature of science: integrating student inquiry, historical cases, and contemporary cases in classroom practice. Science Education, Hoboken, v. 98, n. 3, p. 461-486, 2014. 
BARBOSA, Flavio Tajima; AIRES, Joanez Aparecida. Visões sobre natureza da ciência em artigos publicados em periódicos nacionais da área de ensino de ciências: um olhar para a educação em química. Amazônia (UFPA), v. 14, p. 77-104, 2018.

BATISTETI, Caroline Belotto; ARAÚJO, Eliane Sandra Nabuco de; CALUZZI, João José. As estruturas celulares: o estudo histórico do núcleo e sua contribuição para o ensino de biologia. Filosofia e história da biologia, v. 4, p. 17-42, 2009.

BELTRAN, Maria Helena Roxo; SAITO, Fumikazu; TRINDADE, Lais dos Santos Pinto. História da ciência para a formação de professores. São Paulo: Editora Livraria da Física, 2014.

BRASIL. Ministério da Educação. Secretaria de Educação Básica (SEB). Departamento de Políticas de Ensino Médio. Parâmetros Curriculares Nacionais para o Ensino Médio: Parte III - Ciências da Natureza. Brasília: MEC/ Secretaria de Educação Média e Tecnológica, 2000.

CACHAPUZ, António et al. A necessária renovação do ensino de ciências. São Paulo: Cortez, 2005.

CAMPOS, Carlos; CACHAPUZ, António. Imagens de ciência em manuais de química portugueses. Química Nova, v. 6, p. 23-29, 1997.

EFLIN, Juli T.; GLENNAN, Stuart; REISCH, George. The nature of science: a perspective from the philosophy of science. Journal of research in science the teaching, v. 36, n. 1, p. 107-116, 1999.

FORATO, Thaís Cyrino de Mello; PIETROCOLA, Maurício; MARTINS, Roberto de Andrade. Historiografia e natureza da ciência na sala de aula. Caderno Brasileiro de Ensino de Física, Florianópolis, v. 28, n. 1, p. 27-59, abr. 2011.

GIL-PÉREZ, Daniel et al. Para uma imagem não deformada do trabalho científico. Ciência \& Educação, Bauru, v. 7, n. 2, p. 125-153, 2001.

KRUPCZAK, Carla; AIRES, Joanez Aparecida. A natureza da ciência na formação de professores por meio das controvérsias sociocientíficas: o estado do conhecimento. Revista Ciências \& Ideias, v. 11, p. 01-16, 2020.

LAKATOS, Eva Maria; MARCONI, Marina de Andrade. Fundamentos de metodologia científica. 5. ed. São Paulo: Atlas, 2003.

MARTINS, Roberto de Andrade. A maçã de Newton: história, lendas e tolices. In: SILVA, Cibele Celestino. (Org.). Estudos de história e filosofia das ciências: subsídios para aplicação no ensino. São Paulo: Livraria da Física, 2006. p. 167-189. 
MARTINS, Roberto de Andrade. Ciência versus historiografia: os diferentes níveis discursivos nas obras sobre história da ciência. In: ALFONSO-GOLDFARB, Ana Maria; BELTRAN, Maria Helena Roxo (Orgs.). Escrevendo a história da ciência: tendências, propostas e discussões historiográficas. São Paulo: EDUC / Editora Livraria da Física/Fapesp, 2004. p. 115-145.

MARTINS, Roberto de Andrade. Robert Hooke e a pesquisa microscópica dos seres vivos. Filosofia e História da Biologia, v. 6, n. 1, p. 105-142, 2011.

MATTHEWS, Michael. R. Changing the Focus: From nature of science to features of science. In: Myint Swe Khine (Ed.). Advances in Nature of Science Research: Concepts and Methodologies. Dordrecht: Springer, 2012.

MENDONÇA, Paula Cristina Cardoso. De que conhecimento sobre natureza da ciência estamos falando? Ciência \& Educação, v. 26, p.1-16, 2020.

MORAES, Roque. Análise de conteúdo. Revista Educação, Porto Alegre, v. 22, n. 37, p. 7-32, 1999.

MOURA, Breno. Arsioli. O que é natureza da Ciência e qual sua relação com a história e filosofia da ciência? Revista Brasileira de História da Ciência, Rio de Janeiro, v. 7, n. 1, p. 32-46, 2014.

PRESTES, Maria Elice Brzezinski. Teoria celular: de Hooke a Schwann. São Paulo: Scipione, 1997.

PRESTES, Maria Elice Brzezinski. O whiggismo proposto por Herbert Butterfield. Boletim de História e Filosofia da Biologia, v. 4, n.3, p. 2-4, set. 2010.

QUESADO, Mirna. O papel dos aspectos da natureza da ciência em livros didáticos de ciências: uma análise textual. In: MARTINS, Isabel; GOUVÊA, Guaracira; VILANOVA, Rita (Eds.). O livro didático de Ciências: contextos de exigência, critérios de seleção, práticas de leitura e uso em sala de aula. Rio de Janeiro: [s.n.], 2012, p. 91-104.

SILVA, Elda Cristina Carneiro da. A Teoria Celular em livros didáticos de biologia: uma análise a partir da abordagem histórico-filosófica da ciência. Curitiba: Universidade Federal do Paraná, 2014, 290p. Dissertação (Mestrado)- Programa de Pósgraduação em Educação em Ciências e em Matemática, Curitiba, 2014.

SILVA, Elda Cristina Carneiro da; AIRES, Joanez Aparecida Aires. Panorama histórico da Teoria Celular. História da Ciência e Ensino: construindo interfaces, São Paulo, v. 14, p. 1-18, 2016. 
Edição Especial: I SSAPEC - Simpósio Sul-Americano de Pesquisa em Ensino de Ciências

SILVA, Fernando Marinheiro da. Sobre a indução em Francis Bacon. Revista Urutágua, n. 14 - dez. 07/jan./fev./mar, p. 1-17, 2008.

TALA, Suvi; VESTERINEN, Veli-Matti. Nature of Science contextualized: studying nature of Science with scientists. Science \& Education, v. 24, p. 435-457, 2015.

VITAL, Abigail; GUERRA, Andreia. Textos para ensinar física: princípios historiográficos observados na inserção da história da ciência no ensino. Ciência \& Educação, v.22, n. 2, p. 351-370, 2016. 